\title{
A longitudinal cohort of stress cardiomyopathy assessed with speckle- tracking echocardiography after moderate to severe traumatic brain injury
}

\author{
Raphaël Cinotti ${ }^{1}$, Thierry Le Tourneau ${ }^{2 \dagger}$, Kalyane Bach-Ngohou ${ }^{3 \dagger}$, Maxime Le Courtois du Manoir ${ }^{4}$,
} Bertrand Rozec ${ }^{1,2}$ and Karim Asehnoune ${ }^{4,5^{*}}$ (D)

Keywords: Stress cardiomyopathy, Traumatic brain injury, Speckle-tracking echocardiography

\section{Research letter}

Stress cardiomyopathy is common after subarachnoid haemorrhage (SAH): $36 \%$ of patients display stress cardiomyopathy patterns assessed with speckletracking echography [1], which is a gold standard in the evaluation of left ventricular longitudinal systolic function. After traumatic brain injury (TBI), stress cardiomyopathy has been little described [2]. We performed a monocentric longitudinal study in moderate to severe TBI patients (Glasgow coma score $\leq 12$ ). Consecutive patients were included. This study was approved by the local ethics committee (Groupe Nantais d'Ethique dans le Domaine de la Santé - IRB No. 6.02.2014). We a priori decided to include 100 patients in order to potentially detect 30 patients with sub-clinical stress cardiomyopathy [1]. The primary goal was to assess the incidence of stress cardiomyopathy with speckle-tracking echocardiography and the evolution of the global longitudinal strain (GLS) at day 1 , day 3 , and day 7 . The secondary outcomes were the evolution of 2dimensional echocardiographic parameters (LVEF, mitral E/A and E/E' ratio, mitral $S$ wave, TAPSE). Since stress cardiomyopathy is due to a major catecholamine increase in plasma [3], we explored the adrenergic response by comparing baseline blood levels of metanephrine and normetanephrine in patients with TBI and SAH admitted in our institution, matched on age and baseline GCS (biocollection IBIS - NCT 02426255). We included 100 patients from March 2014 to August 2017. The mean age was 42.6 $( \pm 19.6)$ years and the baseline Glasgow coma score was 7 [4-10]. We included $75(75 \%)$ male and 25 (25\%) female patients. Twenty $(20 \%)$ patients died in the ICU. At day 1, GLS $(-20.3[ \pm 3.6] \%)$ and LVEF $(66[ \pm 11] \%)$ were preserved. The mean GLS was preserved at day $3(-22.2[ \pm 3.6] \%)$ and at day 7 $(-20.7[ \pm 3.3] \%)$. Nine (9\%) patients displayed impaired GLS $(-13.3[-14.5 ;-11.6] \%)$ at baseline. In these patients, there was a significant improvement at

\footnotetext{
* Correspondence: karim.asehnoune@chu-nantes.fr

${ }^{\dagger}$ Thierry Le Tourneau and Kalyane Bach-Ngohou contributed equally to this work.

${ }^{4}$ Anesthesia and Critical Care Department, Hôtel Dieu, University Hospital of Nantes, 1 place Alexis Ricordeau, 44093 Nantes Cedex 9, France

5Laboratoire UPRES EA 3826 "Thérapeutiques cliniques et expérimentales des infections", University Hospital of Nantes, 1 rue Gaston Veil, 44035 Nantes Cedex 1, France

Full list of author information is available at the end of the article
} changes were made. The images or other third party material in this article are included in the article's Creative Commons. licence, unless indicated otherwise in a credit line to the material. If material is not included in the article's Creative Commons licence and your intended use is not permitted by statutory regulation or exceeds the permitted use, you will need to obtain permission directly from the copyright holder. To view a copy of this licence, visit http://creativecommons.org/licenses/by/4.0/ The Creative Commons Public Domain Dedication waiver (http://creativecommons.org/publicdomain/zero/1.0/) applies to the data made available in this article, unless otherwise stated in a credit line to the data. 


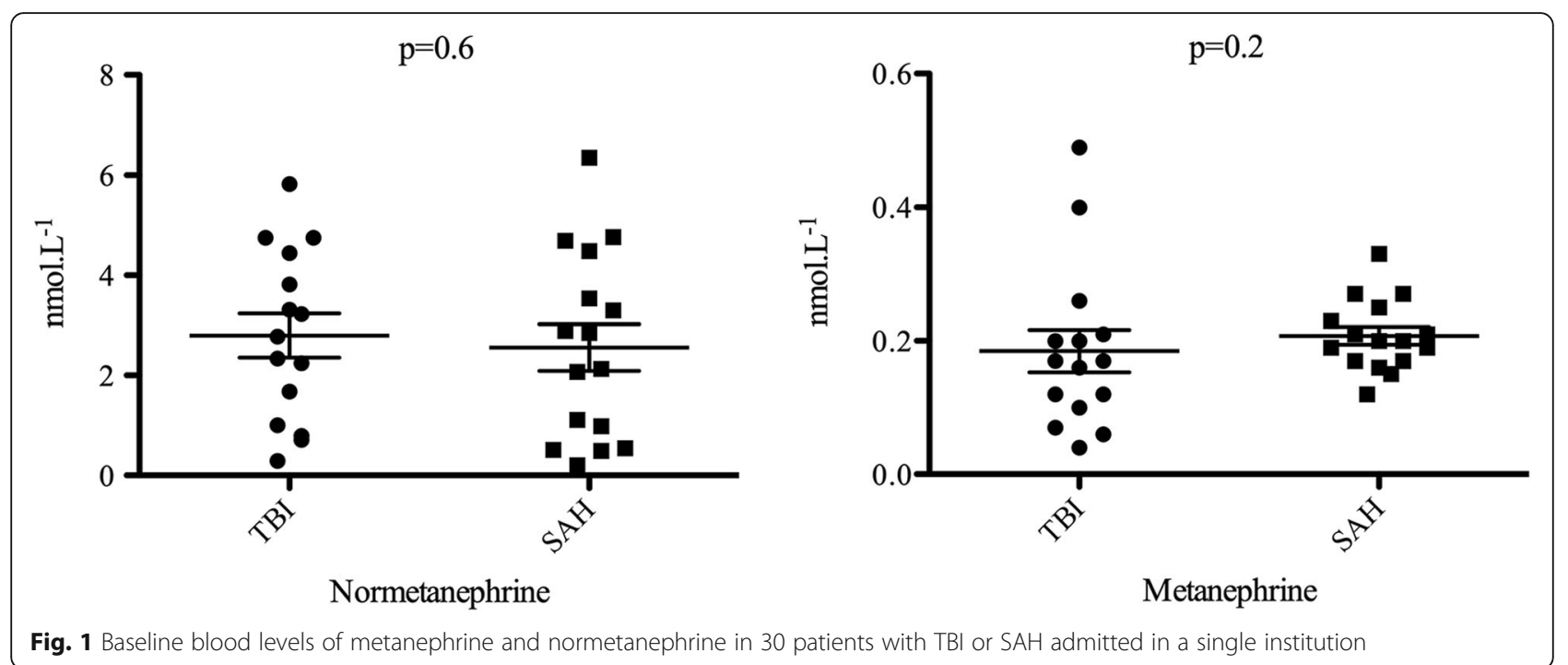

day $3(-22.2[-25.1 ;-18.7] \%)$ and day $7(-21.1[-23.2$; $-18.1 \% \%)(p<0.0001)$, compatible with stress cardiomyopathy. These 9 patients had the same age (32 [23-48] vs 46 [23-60], $p=0.4$ ), had a non-significant baseline ultra-sensitive troponin increase $(16$ [8-229] vs 9 [529] $\left.\mathrm{ng} / \mathrm{mL}^{-1}, p=0.1\right)$, and had similar Glasgow (10 [3-12] vs 7 [4-9], $p=0.3$ ) and Marshall scores ( $p=$ $0.8)$ compared to the rest of the cohort. Three patients suffered from isolated TBI, and two from TBI associated with mild abdominal trauma or vertebral fracture, all due to road traffic accidents. The remaining four patients suffered from isolated TBI after a fall. These mechanisms did not seem to differ from the rest of the cohort.

In the overall cohort, right ventricular TAPSE at day 1 was preserved $(21.6( \pm 7.6) \mathrm{mm})$ and significantly improved at day $3(24.8( \pm 5.3) \mathrm{mm}, p=$ 0.003). There was no significant modification of $\mathrm{LVEF}$, the $\mathrm{E} / \mathrm{A}$ and $\mathrm{E} / \mathrm{E}^{\prime}$ ratios, or lateral $\mathrm{S}$ wave. In order to assess the adrenergic response, we measured baseline metanephrine and normetanephrine blood levels in $15 \mathrm{SAH}$ and $15 \mathrm{TBI}$ patients. There was no significant difference in normetanephrine $(2.5$ [0.7-4.2] nmol/L $\mathrm{L}^{-1}$ vs 2.9 [1-4.4] $\left.\mathrm{nmol} / \mathrm{L}^{-1}, p=0.6\right)$ and metanephrine $\left(0.2[0.17-0.23] \mathrm{nmol} / \mathrm{L}^{-1}\right.$ vs 0.17 [0.1-0.21] $\mathrm{nmol} / \mathrm{L}^{-1}, p=0.2$ ) plasma levels between SAH and TBI patients (Fig. 1), which challenges the adrenergic response as the only trigger for stress cardiomyopathy. However, the plasma levels were not measured just after the onset of brain injury, and considering that the catecholamine levels may rapidly change over time along with the modest sample size, we cannot ascertain that blood levels are comparable between TBI and SAH patients.
Stress cardiomyopathy occurs after traumatic brain injury, recovers promptly, but is less common $(\approx 10 \%)$ than after $\mathrm{SAH}(\approx 35 \%)$. The raised baseline metanephrine and normetanephrine was comparable in our sample of TBI and SAH patients. Sympathetic hyperactivation is perhaps not the only mechanism involved in stress cardiomyopathy.

\section{Abbreviations}

TBI: Traumatic brain injury; GLS: Global longitudinal strain; TTE: Trans-thoracic echocardiography; SAH: Aneurysmal subarachnoid haemorrhage; LVEF: Left ventricular ejection fraction; LV: Left ventricle; ICU: Intensive care unit; GCS: Glasgow Coma Score; TAPSE: Tricuspid annular plane systolic excursion

\section{Acknowledgements}

We thank the biological resource centre for biobanking (CHU Nantes, Hôtel Dieu, Centre de ressources biologiques (CRB), Nantes, F-44093, France (BRIF: BB-0033-00040))

\section{Authors' contributions}

RC and TLT designed the study. RC included the patients, performed the TTEs and GLS analysis and statistical analysis, analysed the results, and wrote the article. KA and TLT analysed the results and wrote the article. KNB performed the metanephrine and normetanephrine dosages, analysed the results, and edited the manuscript. MLM included the patients on site and edited the manuscript. BR analysed the results and edited the manuscript. The author(s) read and approved the final manuscript.

\section{Funding}

Support was provided solely from institutional and/or departmental sources.

Availability of data and materials

The datasets used and/or analysed during the current study are available from the corresponding author on reasonable request.

\section{Ethics approval and consent to participate}

Study approved by the local ethics committee (Groupe Nantais d'Ethique dans le Domaine de la Santé - IRB No. 6.02.2014). Biocollection IBIS, CPP Nantes Ouest IV, IRB approval no. 46/11.

Consent for publication Not applicable 


\section{Competing interests}

Pr Karim Asehnoune received fees from Baxter, Edwards, LFB, Fisher and Payckel. Pr Bertrand Rozec received fees from Baxter, Ethypharm, LFB, NordicPharma, Haemonetics, Fisher and Payckel, AstraZeneca. Pr Thierry Le Tourneau received speaker fees from Philips, Bayer and Shire. The other authors do not have other conflicts of interest to declare.

\section{Author details}

'Anesthesia and Critical Care Department, Hôpital Guillaume et René Laennec, University Hospital of Nantes, Boulevard Jacques Monod, 44800 Saint-Herblain, France. ${ }^{2}$ Institut du Thorax, INSERM UMR1087, University Hospital of Nantes, Nantes, France. ${ }^{3}$ Department of Biochemistry, INSERM U1235, Hôtel Dieu, University Hospital of Nantes, 1 place Alexis Ricordeau, 44093 Nantes Cedex 9, France. ${ }^{4}$ Anesthesia and Critical Care Department, Hôtel Dieu, University Hospital of Nantes, 1 place Alexis Ricordeau, 44093 Nantes Cedex 9, France. ${ }^{5}$ Laboratoire UPRES EA 3826 "Thérapeutiques cliniques et expérimentales des infections", University Hospital of Nantes, 1 rue Gaston Veil, 44035 Nantes Cedex 1, France.

Received: 6 March 2020 Accepted: 30 April 2020

Published online: 12 May 2020

\section{References}

1. Cinotti R, Piriou N, Launey Y, Le Tourneau T, Lamer M, Delater A, et al. Speckle tracking analysis allows sensitive detection of stress cardiomyopathy in severe aneurysmal subarachnoid hemorrhage patients. Intensive Care Med. 2016;42:173-82.

2. Krishnamoorthy V, Rowhani-Rahbar A, Gibbons EF, Rivara FP, Temkin NR, Pontius C, et al. Early systolic dysfunction following traumatic brain injury. Crit Care Med. 2017;45:1028-36.

3. Lyon AR, Rees PS, Prasad S, Poole-Wilson PA, Harding SE. Stress (Takotsubo) cardiomyopathy - a novel pathophysiological hypothesis to explain catecholamine-induced acute myocardial stunning. Nat Clin Pract Cardiovasc Med. 2008;5:22-9.

\section{Publisher's Note}

Springer Nature remains neutral with regard to jurisdictional claims in published maps and institutional affiliations.

Ready to submit your research? Choose BMC and benefit from:
- fast, convenient online submission
- thorough peer review by experienced researchers in your field
- rapid publication on acceptance
- support for research data, including large and complex data types
- gold Open Access which fosters wider collaboration and increased citations
- maximum visibility for your research: over 100M website views per year
At BMC, research is always in progress.
Learn more biomedcentral.com/submissions

